\title{
Social Media and the Variable Impact of Violence Reduction Interventions: Re-Examining Focused Deterrence in Philadelphia
}

\author{
Jordan M. Hyatt ${ }^{1, *}$, James A. Densley ${ }^{2}\left(\mathbb{D}\right.$ and Caterina G. Roman ${ }^{3}(\mathbb{D}$ \\ 1 Department of Criminology and Justice Studies, Drexel University, Philadelphia, PA 19104, USA \\ 2 School of Law Enforcement and Criminal Justice, Metropolitan State University, St. Paul, MN 55445, USA; \\ james.densley@metrostate.edu \\ 3 Department of Criminal Justice, Temple University, Philadelphia, PA 19122, USA; croman@temple.edu \\ * Correspondence: jhyatt@drexel.edu
}

check for updates

Citation: Hyatt, Jordan M., James A. Densley, and Caterina G. Roman. 2021. Social Media and the Variable Impact of Violence Reduction Interventions: Re-Examining Focused Deterrence in Philadelphia. Social Sciences 10: 147. https://doi.org/ 10.3390/socsci10050147

Academic Editors: Matthew Valasik and Shannon E. Reid

Received: 1 February 2021

Accepted: 16 April 2021

Published: 22 April 2021

Publisher's Note: MDPI stays neutral with regard to jurisdictional claims in published maps and institutional affiliations.

Copyright: (C) 2021 by the authors Licensee MDPI, Basel, Switzerland. This article is an open access article distributed under the terms and conditions of the Creative Commons Attribution (CC BY) license (https:/ / creativecommons.org/licenses/by/ $4.0 /)$.

\begin{abstract}
Focused deterrence is a gang violence reduction strategy that relies on a unique mix of strong enforcement messages from law enforcement and judicial officials coupled with the promise of additional services. At the heart of the intervention is a coordinated effort to communicate the costs and consequences of gun violence to identified gang members during face-to-face meetings and additional community messaging. In Philadelphia, focused deterrence was implemented between 2013 and 2016, and although an impact evaluation showed a significant decrease in shootings in targeted areas relative to matched comparison neighborhoods, the effect on targeted gangs was not universal, with some exhibiting no change or an increase in gun-related activity. Here, we employ data on group-level social media usage and content to examine the correlations with gun violence. We find that several factors, including the nature of social media activity by the gang (e.g., extent of activity and who is engaging), are associated with increases in the average rate of gang-attributable shootings during the evaluation period, while content-specific variables (e.g., direct threats towards rivals and law enforcement) were not associated with increases in shootings. Implications for violence reduction policy, including the implementation of focused deterrence, are discussed.
\end{abstract}

Keywords: gangs; violence; shootings; social media; focused deterrence; intervention

\section{Introduction}

Taking on a variety of expressive and pragmatic roles, gang violence, especially involving guns, presents a persistent challenge for law enforcement and communities worldwide (Decker et al. 2021). Violence is often directed at other gangs and is the result of rivalries over activities, territory, or perceptions of respect (Nakamura et al. 2020). Effective strategies to reduce violence are rare and difficult to generalize owing to the unique characteristics of gangs and their environments (Braga et al. 2006). A growing body of research has found that focused deterrence, more recently known as the Group Violence Intervention, can be effective in reducing gang violence (Braga et al. 2018). However, gangs subject to focused deterrence may adapt differently depending on certain factors (Roman et al. 2019). The current study seeks to explore one group of factors that may be associated with the differential responses to focused deterrence observed in Philadelphia, USA: the influence of social media. Social media are increasingly recognized as potentially playing a role in exacerbating gang violence (Patton et al. 2019), and there are unexplored theoretical reasons to believe its use may impact the efficacy of an intervention liked focused deterrence. To examine this relationship, we uniquely link real-world data on gang-specific shooting rates to the nature and intensity of social media usage by those same gangs. We begin by locating the current study in the existing literature on focused deterrence, gang violence, and social media. 


\section{Focused Deterrence and the Philadelphia Experience}

Focused deterrence, an approach in which many "levers" are "pulled" to discourage gangs from engaging in violence, was developed in Boston in the late 1990s (See Kennedy et al. 1996). In the initial model, called Operation Ceasefire (Kennedy et al. 2001), these "levers" consisted of formal agency-level responses from prosecution, law enforcement, and probation, among others, and of offering educational, employment, and social service support. The risks of engaging in violence, and the benefits of abstaining, were communicated to key gang-involved individuals at "call in" meetings. Importantly, these individuals were then instructed to share these messages with other members of their gang.

In Philadelphia, focused deterrence was first implemented in 2013 with "call in" meetings and surveillance and enforcement actions (the unified response to non-compliant participating gangs) running through 2016. Conceived as a multi-agency partnership involving the Philadelphia District Attorney's Office, the Philadelphia Police Department (PPD), the Adult Probation and Parole Department, the First Judicial District (i.e., the local court system), Juvenile Probation, and the Mayor's Office of Criminal Justice, among others, the program largely followed the original Boston model. This meant that the "levers" included increased requests for high bail (by the prosecutor), adjustment of the requirements of community supervision (by adult probation; see Roman et al. 2020 for more context), and the execution of outstaying warrants (by various law enforcement partners). Additionally, unique levers in Philadelphia encouraged rapid responses to utility theft, accumulated non-payment for services (e.g., cable and internet), child support obligations, and a review of public housing subsidies. Social services, coordinated by the Mayor's Office, were also offered to all gang members who were engaging with the program (see Roman et al. 2019, 2020, for additional descriptions of the implementation processes). Throughout the intervention, 14 gangs were the subject of the focused deterrence evaluation.

The "pulling levers" approach on which Philadelphia's intervention was modeled has been replicated and evaluated multiple times, including in Boston and other jurisdictions across the United States and Western Europe. Research has shown that focused deterrence can reduce crime. Recent studies have shown associated reductions in violence observed in large (e.g., Los Angeles; Tita et al. 2003), medium (e.g., New Orleans; Corsaro and Engel 2015), and smaller (e.g., Lowell (MA); Braga 2008) cities. Its adaptation in Glasgow, Scotland, derived from a version of the model in Cincinnati, is credited with large reductions in serious youth violence (Deuchar 2013; Graham 2016; Williams et al. 2014). One systematic review aggregated the most rigorous of these jurisdiction-level studies $(n=10)$ and found that $90 \%$ of them identified a statistically significant reduction in crime attributable to the intervention (Braga and Weisburd 2012). A more recent review by the same authors found smaller but significant reductions in violence, though variation in impact by program type, goal, and outcomes was identifiable due to the larger sample size $(n=24)$ (Braga et al. 2018). The evaluations of the sites that implemented programs focused specifically on gangs (as opposed to individuals or drug markets) witnessed the largest effects.

Fewer studies have sought to examine how specific gangs responded to focused deterrence. Braga et al. (2014), for example, employed a quasi-experimental approach in Boston to compare a sample of comparison gangs that were similar to the targeted gangs but that were not subject to the intervention themselves. A side-by-side comparison showed that the shootings among the participating gangs decreased by $31 \%$, a statistically significant reduction. Similar results were identified in Chicago, where the gangs that participated in a "call-in" demonstrated a 23\% reduction in shootings (Papachristos and Kirk 2015).

The evaluation in Philadelphia followed the model employed by Braga et al. (2018) and sought to identify not only the community-wide impact of the strategy on gun violence but also assess the impact at the gang level (Roman et al. 2019). In Philadelphia, all the targeted gangs resided in the same region of the city. They employed a propensity scoring and matching design to pair communities where the gangs were involved in focused deterrence with similar neighborhoods, including in terms of baseline violence, gang 
activity, and socio-demographics, where the gangs were not selected for participation. The community-level difference-in-differences results showed a statistically significant reduction in shootings in the 24 months after the implementation of focused deterrence when compared to the matched comparison areas. The gang-specific analyses focused on two metrics: the number of shootings in the geographic area(s) associated with the targeted gangs as well as the number of shootings in which an identified member of a given gang was identified as the perpetrator. Although shootings in the areas associated with the targeted gangs decreased more than the comparison gangs' areas (which also decreased, to a lesser extent), these findings did not reach statistical significance. A descriptive examination of the average change per quarter of the number of with a gang-identified perpetrator highlights one potential challenge (Figure 1, below). Of the 14 gangs that participated, the majority responded positively to focused deterrence, as was anticipated. However, three gangs bucked that trend and were associated with more shootings after efforts were made to prevent violence; the intervention backfired for those gangs. One gang had neither a reduction in shootings nor an increase.

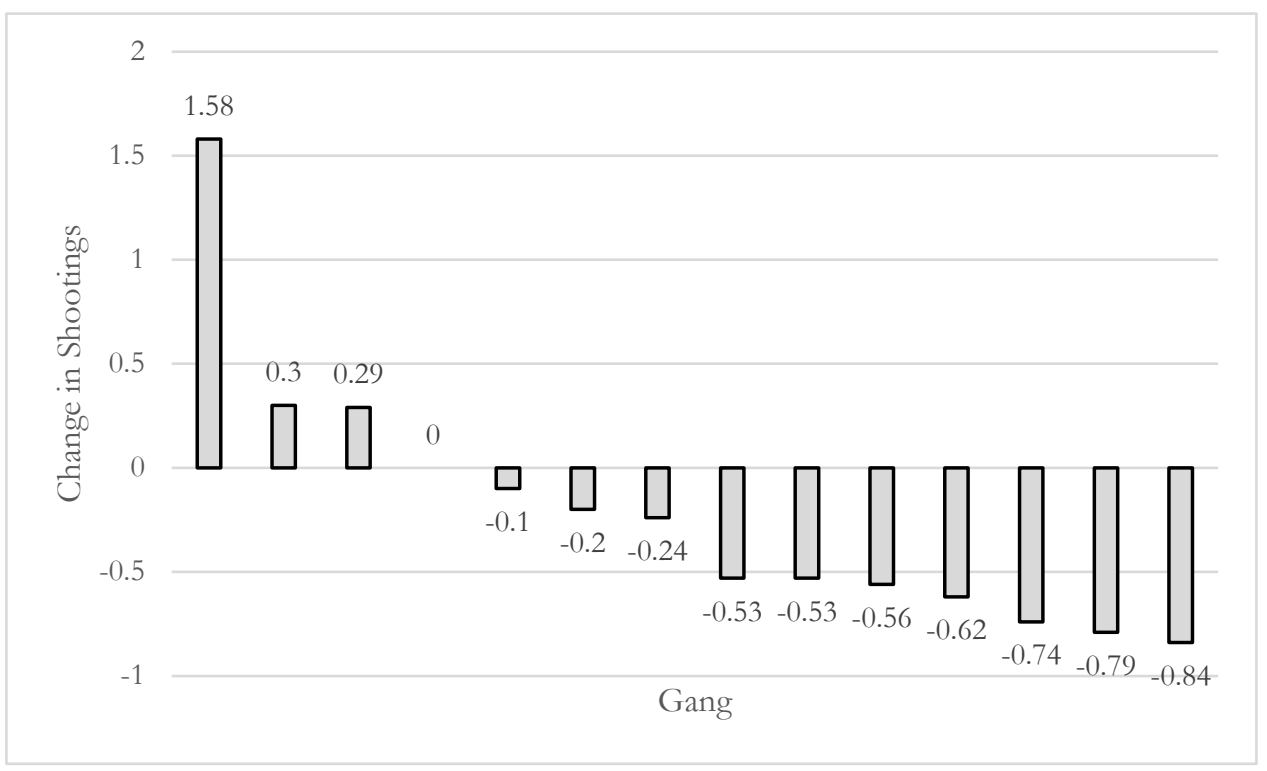

Figure 1. Average change per quarter in counts of gang-related (by known perpetrator) shootings $(\mathrm{n}=14)$. Note: Post period for each gang begins in the first quarter that the gang was "called in".

In considering these findings, Roman and colleagues noted that even when targeted with the same, generally effective strategy, gangs may not always respond the same way (Roman et al. 2019). One possible source of this variable response may be the extent to which gangs differentially engaged with social media, especially concerning threatening rhetoric that could lead to intra-gang violence. In other words, gangs more likely to be using social media as a venue for communication may be less likely to pay attention to the deterrent message of focused deterrence-a lesson that centers on reinforcing a sense of collective accountability. Similarly, high levels of this type of online activity could bring a gang into virtual contact with other gangs or individuals engaged in illegal activity that they would not otherwise encounter; these increased opportunities for confrontation could translate into street-based violence if the gangs fight or if they collude to commit new crimes. Alternatively, the online and physical worlds may not overlap in this space; social media activity may function independently from face-to-face actions. In the current inquiry, we seek to develop preliminary evidence on this dynamic, though we first consider the theoretical and practical landscape. 


\section{Gang Violence on Social Media}

Social media have become a dominant force in modern public discourse in just over two decades (Dewing 2010; Zuboff 2018). Since their inception, social media sites have been designed to encourage and facilitate interpersonal communication using videos, pictures, and written messages; regulation of illegal content has been largely ineffective at preventing the dissemination of violent rhetoric and, in some cases, actions (Bock 2012; Patton et al. 2013). This has resulted in the creation of an online extension of the physical world where friends and rivals can speak directly; street gangs have expanded their traditional means of communication (Goldman et al. 2014) to adapt to this new reality. The impact of the shift from the physical to the virtual world, especially within the context of social media, can impact the psychological and social dynamics of communication, often requiring a real-world response (see, e.g., Fedushko et al. 2021).

There has been an explosion of research examining gangs' use of the internet in the last decade (for reviews, see Densley 2020; Peterson and Densley 2017; Pyrooz and Moule 2019), including a recent Eurogang edited volume titled Gangs in the Era of Internet and Social Media (Melde and Weerman 2020). Examining the content and language used by gang members on social media has taken a prominent role in these examinations. For example, an examination of the Twitter profile of one murdered Chicago gang member demonstrated that such communications are often used to promote gang affiliations, report on violent acts, and to facilitate networking between geographically diverse gangs (Patton et al. 2017b). Stuart (2020), drawing on ethnographic research in Chicago, argues that social media are used to openly challenge the strength and masculinity of rival gangs, an action that may engender violent retaliation in a certain subset of instances but not generally. Patton et al. (2019) highlighted the interactive way gangs use Twitter and find that certain types of messages (e.g., disses, call-outs, and threats) have a high potential to engineer a violent response. The mechanisms by which social media may or may not directly facilitate gang violence generally are not well specified nor measured. These limitations are drawn, in part, from a lack of clear, empirical data on individual-level social media usage by gangs that can be linked to changes in offline violence. However, the descriptive, critical examination of social media by and about gang members has given rise to theoretically driven linkages between online activity and "real world" violence.

Even if much of what gang members do online is the same as the activity of non-gang members (Moule et al. 2013, 2014), what makes gang members unique is their use of the internet to explicitly promote their criminal exploits and to insult and intimidate rivals (Johnson and Schell-Busey 2016; Pawelz and Elvers 2018). However, a recent study of gangs in London found there were "differential adaptations" to social media among gangs, including gangs that occupied the same geographic spaces (Whittaker et al. 2020). The authors attributed this to a "generation gap". They argued that newer gangs and younger gang members, especially those with tenuous "street capital" (Harding 2014), had more to gain and less to lose from signaling their reputations online versus more durable gangs and more senior gang members, who had street capital in the bank and could not afford the extra scrutiny that social media attention provided (see also, Densley 2020).

The nature of the online forum itself may also influence the nature of the discourse for gang members. Online disinhibition (anonymity) might mean youth act up more online than they would in person, magnifying the exacerbating tensions between gangs which can then later lead to violence in the streets (Patton et al. 2017b). Life online remains anchored in the lived experience (Lane 2018; Roks et al. 2020), which is why references to physical territories, such as street signs or zip codes (Densley 2013; Irwin-Rogers et al. 2018), are a fixture of "internet banging" (Patton et al. 2013). Leverso and Hsiao (2020) learned from digital trace data scraped from a public Facebook page about Chicago Latino gangs (resulting in over 140,000 posts, likes, comments, and comment replies) and combined with law enforcement data on the geographic locations of gangs, that fighting among gang members in the online environment was conditional on the type of post displayed, but also the geographic proximity of gang territory. They found gang members using social media 
to interact with other gangs in faraway locales as well as individuals nearby, but the tone and tenor of that communication often reflected the degree of physical distance. Gangs living nearby, therefore, may have a much tighter (and rapid) relationship between online communication and what happens on the streets.

At the same time, the social distance that social media create can help diffuse tensions and de-escalate violence. In nature and many non-delinquent social engagements, one method of self-protection is presenting as more intimidating, larger, or more dangerous than is the case (Felson 2006; Howell 2007). Social media affords gangs the same illusion of size, strength, and spread (Densley 2013). For gang members living in Chicago's most dangerous neighborhoods, urban ethnographer Forrest Stuart (2020) found that exaggerated virtual identities created barriers to violence. By presenting themselves as scarier and more violent than they were in real life, including posting photographs of themselves posing in crowds of dangerous-looking people or holding borrowed guns, gang members could deter rival predation. Authenticity still mattered, however, and if rivals called someone on their bluff or caught them "lacking" (i.e., unwilling to take the bait), especially live on camera, then violent retaliation could follow. These findings hold important implications for law enforcement, who have been criticized (e.g., Lane et al. 2018; Patton et al. 2017a) for taking online claims at face value and unduly criminalizing actions that everyone on social media is guilty of-portraying their lives as more glamorous and exciting than they are, for the sake of retweets or likes. However, it should be noted that, given the nature of the ethnographic data and methods, the study findings cannot be broadly generalized and have not yet been validated by other studies by examining gangs outside of Chicago or with a larger sample of gangs.

\section{Social Media and Focused Deterrence}

There are a few reasons why social media could mediate, or even undermine, gang interventions such as focused deterrence. For example, focused deterrence requires "community moral voices" such as pastors and parents to reinforce or "retail" the law enforcement message that violence is wrong and will incur consequences (Densley and Jones 2016; Kennedy et al. 2001). However, in the age of social media, these voices cannot reach gang members with the same degree of constancy and invasiveness that social media feeds can, as they are delivered to phones and computers constantly. Additionally, both law enforcement and engaged community members are competing against persuasive digital design techniques such as push notifications and the endless scroll of a newsfeed, which capture the hearts and minds of users and create a feedback loop that keeps gang members (and non-gang members) attached their devices. Technology companies such as Facebook (which also owns Instagram), Google (which owns YouTube), and Twitter profit from keeping users on their platforms because more human engagement means more advertising dollars-their primary source of income in the absence of subscription and usage fees (Zuboff 2018). They facilitate and often encourage discourse with limited focus on the content to monetize their respective platforms.

Relatedly, social media platforms are designed to profit from "confirmation bias" (Nickerson 1998), the natural human tendency to seek, "like," and "share" (in social media parlance) new information that aligns with strongly held preexisting beliefs. To keep people online, they rely on adaptive algorithms that assess interests and flood users with content that is similar to what they have liked previously. This self-reinforcing cycle makes it difficult to change old habits such as violence and may bring together similar messages from competing gangs. Someone subject to focused deterrence may want to avoid gang content both in-person and online, but personalized media feeds based on past click behavior and search history instead create "filter bubbles" that make encountering aspects of active gang life unavoidable (Pariser 2011). The social media echo chamber can also provide near-constant reaffirmation for the gang by silencing outside voices and contradicting any intervention's countervailing messaging (Eckberg et al. 2018). Social media algorithms instead promote gang content that sparks outrage and which may 
amplify biases. This need not be public or direct threats from rival gang members. Simply being reminded constantly of friends killed in action might be enough. For example, analyses of Twitter content have found that expressions of grief and loss predict increased future aggression among gang-involved youth (Patton et al. 2018).

The noise from public and direct threats posted on the internet may well "drown out" any focused deterrence messaging, especially those on social media that are perceived as immediate and localized threats of violence or insults to gang identity. Actively posting self-incriminating content that incites violence is so "costly" (Densley 2013) that it may well be an indirect measure of a gang or gang member's immunity to focused deterrence messaging; their willingness to be violent and contempt for the law (Sandberg and Ugelvik 2016). Law enforcement has, with increasing frequency, sought to leverage these public communications to prevent and prosecute criminal activity (Brayne 2017). At the same time, it is difficult for law enforcement and social service providers to proactively monitor the street for signs of impending violence when those high-risk individuals are not out in the street (Patton et al. 2016), and without input from "domain experts" (i.e., people fluent in gang content) such as ex-gang members, the cultural terms or coded language hidden in memes and emojis that may provoke violence could go undetected (Frey et al. 2020; Patton et al. 2019).

\section{Materials and Methods}

The Data

The data used in this study were derived from the administrative records and primary data employed in the primary evaluation of focused deterrence in Philadelphia (see Roman et al. 2019). These data describing general gang characteristics were constructed during a series of large audit meetings held during the evaluation period and led by members of the research team. In these retrospective, multi-agency meetings, law enforcement leadership, front-line officers, and task force members met to aggregate information about each of the gangs involved in the focused deterrence intervention. Information was provided by various individuals with first-hand knowledge about the gangs, discussed among all audit participants, and a consensus was reached (Roman et al. 2019). For each gang, the audit participants worked through the names of every possible member, adding and removing individuals as determined by group consensus. Prior studies have shown this to be a valid measure of determining the nature and extent of gang activity (see, e.g., Gravel and Tita 2015). The result of the audit was a holistic picture of the size, activity history, and activities of each gang (for a general discussion of this approach, see SierraArévalo and Papachristos 2015, 2017).

The current study employs three types of variables, two of which are drawn from the gang audit procedures described above. The first type is gang variables, which focus on describing the size and general nature of the gang. While these data are, by nature, estimates, they represent the best available data on these gangs and their basic descriptive statistics and activity level. Importantly, the data on each of these gangs were developed by the same individuals and using the same procedures; though imprecision may be an issue, between-gang comparisons are supportable.

In this set of gang variables, the number of rivals indicates the count of other gangs the subject gang was actively feuding with at the time of the audit. Heat level is a measure of how violent and/or serious of a threat a gang was perceived to be by local law enforcement at the beginning of the initiative (in the second quarter of 2013) using a scale that ran from inactive to highly active. Count of members is the number of core participants derived from the audit; gang associates provide the same information, but for individuals less central to the core activities and/or direction of the gang. Finally, average age reports the average age of known members of the gang (not associates) based on administrative records (i.e., arrest and court records).

The second set of gang variables are the social media variables, developed from a different source, though using a largely similar process. A series of audits focusing only on 
social media usage was held with the intelligence unit officers assigned to the gang task force in the focused deterrence target area. In this role, these officers were responsible for the collection, oversight, and synthesis of information on social media activity by the gangs in their assigned region who were under investigation and/or surveillance. As with the larger audits, data were obtained independently from each officer and then cross-validated. This audit was conducted in early 2018 as interim impact analysis indicated that not all gangs were responding to the focused deterrence messaging. At this time, the evaluation window had concluded, but data collection for the study was still active. The variables focused on estimates for and descriptions of specific online activities (e.g., feuds, threats to law enforcement, and displays of violence and illegal items such as guns and drugs), overall usage of various social media sites, estimates of how active social media usage was within the gang, percent of high-visibility gang members using social media, and estimates of the prevalence of violent content by gang members across all platforms.

In these data, the percent active on social media variable captures the percent of all known gang members believed to use social media for gang-centric activities. Percent impact indicates the number of high "impact" individuals from the gang, often leaders and senior members, who were known to use social media for gang-related activities. The overall social media usage variable captures the total amount of social media usage attributable to the gang as compared to other gangs in the city. Illegal content (e.g., images or discussion of guns, cash, and/or narcotics) and violent content convey similar information about these subtypes of postings by the gang. Due to the difficulty in ascertaining precise levels of social media activity, these data are captured in measures using categorical values (ranging from no activity to high levels of activity of that type) with overall levels of gang activity in the city at the time used as a reference. Similarly, variables regarding threats to law enforcement, rival gangs, and other activity are constructed as binary variables reflecting the presence or absence of the subtype of online activity during the focused deterrence evaluation period. Finally, percent violent content is an estimate of what percentage of all content posted by the gang and gang-involved individuals were estimated to be explicitly violent (e.g., direct threats, boasts of past violence) in nature.

Finally, the gang shootings variable is the average quarterly change in gang-involved shootings, comparing the period before the gang was first called in to a notification meeting to the period after the gang's first call-in meeting. The values for this variable were derived from the regression models in the main impact analyses (Roman et al. 2019). For these analyses, a gang-involved shooting is a shooting in which the PPD identified the perpetrator as a member of a targeted gang. The research team had collected data on every shooting in the target area between January 2009 and 1 April 2015. If there were any shootings where the research team did not have coded shooting data from the PPD, the intelligence analysts re-reviewed the spreadsheet to validate the data entry.

The auditing process employed for this study and related work (see Roman et al. 2019) was designed to quantify the often-subjective perceptions of law enforcement actors regarding various aspects of gang activity in Philadelphia in a consistent manner. Modeled off previous successfully implemented audits (see e.g., Kennedy et al. 1996; Papachristos and Kirk 2015), the auditing process included multiple efforts to cross-validate the data collected between several stakeholder groups and actors, both between gangs and over time, to develop the most robust measures possible. This is important as the construction of gang databases is an exercise fraught with challenges, especially in operationalizing definitions of activity and membership (Densley and Pyrooz 2020; Kennedy 2009). In particular, questions about the accuracy (e.g., are audit assessments reflective of the "real" world?), reliability (e.g., are audit assessments consistent over time and repeated measurements?), and validity (e.g., are audit assessments focusing on the correct measures of activity?) persist. While difficult to authoritatively answer, the audit data, derived using the processes above, represent the best and, in some cases, only data on gang-level activity available to both the research team and local law enforcement. The audit process also includes several procedural checks, including verification of all assessments using multiple types of data 
and/or more than one reporting source, to limit the potential influences of individualor system-level biases. While potentially imperfect, social network analyses have shown that, beyond the focused deterrence model, data derived from audits can successfully guide interventional efforts in policing (Sierra-Arévalo and Papachristos 2015) and violence reduction (Tita and Radil 2011).

\section{Results}

To examine the associations between social media and gang violence, we first consider the descriptive statistics for the variables developed during the social media audits. These data present a unique picture of the perceived online activities of the subset of gangs that were included in the evaluation. Subsequently, we seek to examine the associations between the factors detailed above and changes in the observed rates of violence. We do so by calculating partial correlations between the shooting outcome for all fourteen gangs, the average quarterly change in shootings over time, and the social media variables. In these comparisons, we control for the gang variables to better identify the focal relationships.

We first consider the variables relating to gang characteristics and compare means, ranges, and standard deviations for two aggregate groups. Table 1, below, reports average values for the group of gangs that demonstrated an increase in shootings $(n=3)$ during focused deterrence as compared to those reporting a decrease $(n=9)$. Note that, for this set of analyses only, we omit the single gang for which no change in shooting rates was reported as this outcome is not appropriately attributable to either the "increase" or "decrease" groups and including a single gang as a distinct category could result in that gang becoming identifiable.

Table 1. Gang-level descriptive statistics, by change in shootings.

\begin{tabular}{cccccccccccc}
\hline \multicolumn{1}{c}{ Gangs that Increased Shootings during Focused Deterrence $(n=3)$} & \multicolumn{3}{c}{$\begin{array}{c}\text { Gangs that Decreased Shootings during Focused } \\
\text { Deterrence }(n=10)\end{array}$} \\
\hline & N & Min & Max & Mean & Std. Deviation & N & Min & Max & Mean & Std. Deviation \\
\hline $\begin{array}{c}\text { Number of known and } \\
\text { active rival gangs }\end{array}$ & 3 & 3 & 5 & 4.00 & 1.00 & 10 & 1 & 5 & 3.00 & 1.333 \\
\hline $\begin{array}{c}\text { "Heat Level”, as assessed } \\
\text { by law enforcement }\end{array}$ & 3 & 3 & 3 & 3.00 & 0.00 & 10 & 2 & 3 & 2.80 & 0.33 \\
\hline $\begin{array}{c}\text { Number of known gang } \\
\text { members }\end{array}$ & 3 & 22 & 123 & 69.33 & 50.79 & 9 & 7 & 122 & 49.56 & 37.70 \\
\hline $\begin{array}{c}\text { Number of known } \\
\text { associates to the gang }\end{array}$ & 3 & 5 & 34 & 15.67 & 15.94 & 10 & 0 & 33 & 11.60 \\
\hline $\begin{array}{c}\text { Average age of gang } \\
\text { members }\end{array}$ & 3 & 23 & 25 & 24.00 & 1.00 & 9 & 23 & 32 & 25.88 \\
\hline $\begin{array}{c}\text { Average number of times } \\
\text { called in during FD }\end{array}$ & 3 & 2 & 4 & 2.667 & 1.15 & 8 & 3 & 4 & 3.875 \\
\hline
\end{tabular}

NOTE: FD = focused deterrence.

There are slight observable differences between the gangs that responded positively ( $n=10$, average change in shooting incidents per quarter: -0.51$)$ to focused deterrence and those that did not $(n=3$, average change in shooting incidents per quarter +0.72$)$ (see Figure 1 above). On average, the gangs with more shootings during the implementation of the strategy than before focused deterrence had more rivals with whom they were actively feuding ( 4 v. 3 known rival gangs) and, not surprisingly, had been deemed "hotter" about their observed levels of criminal activity $(3.0 \mathrm{v}$. 2.80) at the start of the strategy (e.g., 2013). They were also slightly larger, on average (85 total individuals v. 49.56 total individuals). Finally, though most gang members were young, the more violent gangs had members who were 1.89 years younger than their peers in the less violent gangs, on average. Taken together, these data suggest that there are some differences between the overall characteristics for the gangs who maintained or increased their shootings post- 
implementation of focused deterrence versus those that had fewer shootings. This is particularly true concerning their size, but, overall, this variation is not overwhelmingly large, nor were any significant outliers identified. This is unsurprising because the gangs that were included in the intervention were all located in the same area of the city and met the common criteria for inclusion in focused deterrence.

We next turn our attention away from the streets and towards the virtual world. Detailed in Table 2 below, these data describe average levels and the nature of social media activity attributable to the gangs, again disaggregated by their response to the intervention.

Table 2. Gang-level social media descriptive statistics by change in shootings.

\begin{tabular}{|c|c|c|c|c|c|c|c|c|c|c|}
\hline \multicolumn{6}{|c|}{ Gangs That Increased Shootings during Focused Deterrence $(n=3)$} & \multicolumn{5}{|c|}{$\begin{array}{c}\text { Gangs That Decreased Shootings during Focused } \\
\text { Deterrence }(n=9)\end{array}$} \\
\hline & $\mathbf{N}$ & Min & Max & Mean & Std. Deviation & $\mathbf{N}$ & Min & Max & Mean & Std. Deviation \\
\hline $\begin{array}{l}\text { Number of known and } \\
\text { active rival gangs }\end{array}$ & 3 & 3 & 5 & 4.00 & 1.00 & 9 & 2 & 5 & 3.22 & 1.20 \\
\hline $\begin{array}{l}\text { "Heat Level", as assessed } \\
\text { by law enforcement }\end{array}$ & 3 & 3 & 3 & 3.00 & 0.00 & 9 & 2 & 3 & 2.89 & 0.3 \\
\hline $\begin{array}{l}\text { Number of known gang } \\
\text { members }\end{array}$ & 3 & 22 & 123 & 69.33 & 50.79 & 9 & 7 & 122 & 49.56 & 37.70 \\
\hline $\begin{array}{l}\text { Number of known } \\
\text { associates to the gang }\end{array}$ & 3 & 5 & 34 & 15.67 & 15.94 & 9 & 0 & 33 & 12.00 & 12.15 \\
\hline $\begin{array}{l}\text { Average age of gang } \\
\text { members }\end{array}$ & 3 & 23 & 25 & 24.000 & 1.00 & 9 & 23 & 32 & 25.88 & 3.29 \\
\hline $\begin{array}{l}\text { Average number of times } \\
\text { called in during FD }\end{array}$ & 3 & 2 & 4 & 2.667 & 1.15 & 8 & 3 & 4 & 3.87 & 0.35 \\
\hline
\end{tabular}

NOTE: FD = focused deterrence.

As was the case with the gang-level descriptive statistics, a visual examination of Table 2 shows that there were small differences between the two groups' online activities. The gangs that did not respond to the intervention, for example, were overall more active on social media ( $85 \%$ v. $68.8 \%)$, and a higher proportion of high visibility impact members were engaged in these online activities (93.3\% v. 78.33\%). Unsurprisingly, this also translated to a higher aggregate score of social media usage (2.67 out of $3 \mathrm{v}$. 2.11), as well as the scores for violent (2.0 out of 3.0 v. 1.67) and general illegal (2.67 out of 3.0 v. 1.89) postings. Finally, small differences $(3.3 \%)$ in the number of overall messages that were violent can also be observed. The differences in this area appear to be the most pronounced concerning the pervasiveness of use among high-impact leaders and the general membership, though the gangs that did not desist have higher average levels of violent and illegal rhetoric.

Finally, we calculated a series of partial correlations between our proxy for violence during the evaluation period, the average change in the rate of shootings post engagement, and the various social media variables described above. Data from all fourteen gangs who were enrolled in the evaluation are used in this analysis. In calculating these statistics, we control for the gang-level variables (heat level, number of reported rival gangs, average age, size (members and associates), and the number of individuals on probation in the gang. We also control for the number of times the gangs were "called-in" during the evaluation period. As reported in Table 3 below, these associations provide some insight into both the direction and potential strength of the relationship between virtual behaviors and violence on the streets. 
Table 3. Partial correlations between social media activity and shootings, after implementation of focused deterrence $(\mathrm{n}=14)$.

\begin{tabular}{|c|c|c|c|c|c|c|c|c|c|c|c|}
\hline & & \multicolumn{10}{|c|}{ Social Media Variables } \\
\hline & & $\begin{array}{c}\% \\
\text { Active }\end{array}$ & $\begin{array}{c}\% \\
\text { Impact }\end{array}$ & $\begin{array}{c}\text { Overall } \\
\text { Social } \\
\text { Media }\end{array}$ & $\begin{array}{l}\text { Illicit } \\
\text { Social } \\
\text { Media }\end{array}$ & $\begin{array}{c}\text { Viol. } \\
\text { Social } \\
\text { Media }\end{array}$ & $\begin{array}{c}\text { \% } \\
\text { Violent } \\
\text { Posts }\end{array}$ & $\begin{array}{l}\text { Feud } \\
\text { Online }\end{array}$ & $\begin{array}{l}\text { Threat: } \\
\text { Rivals }\end{array}$ & $\begin{array}{l}\text { Threat: } \\
\text { Law } \\
\text { Enforce }\end{array}$ & $\begin{array}{l}\text { Other } \\
\text { Activity }\end{array}$ \\
\hline \multirow[t]{3}{*}{$\begin{array}{l}\text { Average change } \\
\text { per quarter in } \\
\text { counts of } \\
\text { gang-related } \\
\text { shootings }\end{array}$} & $\begin{array}{l}\text { Correlation } \\
\text { Coef. }\end{array}$ & 0.67 & 0.90 & 0.89 & 0.97 & 1.00 & -0.45 & 0.35 & 0.39 & 0.51 & 0.63 \\
\hline & $\begin{array}{l}\text { Significance } \\
\text { (2-tailed) }\end{array}$ & 0.33 & $\begin{array}{c}0.10 \\
* *\end{array}$ & $\begin{array}{c}0.10 \\
* *\end{array}$ & $\begin{array}{c}0.03 \\
*\end{array}$ & $\begin{array}{c}0.00 \\
*\end{array}$ & 0.55 & 0.65 & 0.61 & 0.49 & 0.37 \\
\hline & $\mathrm{df}$ & 2 & 2 & 2 & 2 & 2 & 2 & 2 & 2 & 2 & 2 \\
\hline
\end{tabular}

An examination of the correlation coefficients highlights a range of associations between social media usages among the fourteen gangs and the number of shootings in which they were involved after becoming involved in the evaluation. The coefficient reported here is one that must fall between -1 and +1 , with larger positive numbers indicating a stronger positive relationship, negative numbers indicating a stronger negative relationship, and 0 indicating no relationship is described by the data in the sample. It is illustrative to consider these variables in two subgroups: first, measures of how active the gang was online and, secondly, descriptions of the kinds of content that the gang posted online.

Overall, some of the variables that were associated with an increase in shootings after the implementation of focused deterrence were those that described the general presence of the gang on social media. For example, the overall percentage of "impact" players, generally leaders and highly visible members, was significantly associated with higher shooting rates $(\mathrm{r}=0.89, p \geq 0.1)$. The same is true about the overall level of social media usage attributable to the gang $(\mathrm{r}=0.88, p \geq 0.1)$. While failing to reach statistical significance, the overall percent of known gang members who were active on social media demonstrated a similar pattern in the direction of the correlational relationship $(r=0.67$, ns) with more gangs with more identified shootings during focused deterrence.

A consideration of the type of content that the gang was seen as having posted to social media paints a more complicated picture of the relationship between the internet and the street. Three of the variables categorically describe the nature of the gang's general activity on social media. Illicit postings, those that reference illegal activities but are not directly violent (e.g., post picturing or discussing guns, drugs, or ill-gotten cash), are significantly and strongly associated with higher shooting rates $(r=0.97, p \geq 0.05)$. A similarly constructed variable capturing perceptions of overly violent content (e.g., threats and warnings) also reached statistical significance rates in this analysis $(r=0.99$, $p \geq 0.05$ ). Similarly, the variable capturing the overall level of social media engagement attributed to the gang was significant and positive $(r=0.88, p \geq 0.1)$. However, the variables that capture specific kinds of social media activity discussed as likely to spill over into the streets had a different relationship with shootings in this analysis. Estimates of the percentage of the number of a gang's violent postings were negatively associated with shooting $(\mathrm{r}=-0.45, \mathrm{~ns})$, a surprising result. Other measures assessing specific kinds of social media activity were also correlated with a positive change in the number of shootings after their experience with focused deterrence began, though none reached statistical significance: engagement in online feuds $(r=0.35)$, threats to rival gangs $(r=0.39)$, posting of other, illicit types $(r=0.62)$. Finally, the correlation with our measure of the extent to which the gang threatened law enforcement officers online was also positive, though not statistically significant $(r=0.51)$. 


\section{Discussion}

Violence, especially shootings, can be pervasive and deeply engrained into gangrelated actions (Decker 1996). This has presented a persistent challenge for both law enforcement and public policymakers (see, e.g., Papachristos 2011). Focused deterrence is one shooting reduction intervention that has been both widely adopted and enjoys a fairly robust and supportive foundation within the evaluation literature (see Kennedy et al. 1996; Kennedy 2019; Braga and Weisburd 2012; Braga et al. 2018). Social media, over the past ten years, have taken on a central role in how many gangs develop and express their identity (Storrod and Densley 2017), and it has been argued that they may contribute to subsequent violence (Patton et al. 2019). Despite these parallel and contemporaneous trends, few studies have sought to analytically examine the impact of social media usage by gangs within the framework of a violence reduction intervention. There are many reasons for this, including challenges in obtaining the relevant empirical data and rapid changes in social media usage and platforms (Irwin-Rogers et al. 2018). The results of the current study, which makes these preliminary connections, can inform our theoretical understanding of the nexus between online activity and street violence, as well as provide evidence of new avenues of emphasis for focused deterrence.

The descriptive statistics on gang-level social media usage paint a picture that is largely consistent with the profile that was developed within ethnographic and qualitative studies in this area. As multiple scholars have noted, gang communications made online can be both expressive (e.g., Stuart 2020) and utilitarian (e.g., Johnson and Schell-Busey 2016). Threats of violence that do not translate to action may be considered the former, while discussion of criminal activity may be the latter; we find evidence of both. These data also show that, on average, the gangs in this study promoted violence in almost one-third of their postings; all gangs had a group-level online presence, and not a single gang was scored as not using that platform to engage in activity online related to illegal activities.

These descriptive results reinforce the argument that social media may play a dominant role in general communication for gangs in the current moment. For the gangs in this study, even a cursory examination of the descriptive data shows that not all social media postings are equal, with some being used for expressive and arguably non-violence purposes. For example, the percent of violent postings ranged from $15 \%$ to $60 \%$ across all gangs in the sample. This range was largely the same within the gangs who were grouped based on this response to focused deterrence, suggesting that while usage itself is pervasive, gangs employ social media to deliver a wide range of rhetoric. The support of characteristics of communication common in the current literature strengthens the robustness of the assumptions that underlie them as the current study relies on a different methodological approach and investigates gangs in a previously unexamined jurisdiction.

A comparison of those gangs that had an increased rate of shootings with those that had a decreased rate of shootings during focused deterrence shows some differentials of note. We find, as others have (e.g., Harding 2014), that the gangs that increased their shootings are younger by about two years on average. They are also slightly larger in terms of the number of members. This difference is compounded by the fact that a higher percentage of the gang, both overall and of the "impact" members, are engaging in these forums. This, in turn, translates to a higher overall social media usage score and, in all likelihood, a larger and more visible footprint for the gang on the internet. This reinforces the commonly made assertion that gang intervention strategies have evolved to integrate social media as an important venue for communication (Bock 2012; Densley 2020; Pyrooz and Moule 2019).

Our results paint a more complex picture about the correlates between online activity and shootings among all of the gangs in this sample. On one hand, we find some differentiation based on the types of social media content. Directly threatening rivals, as well as being willing to openly challenge law enforcement, which can easily be assumed to translate to the kinds of in-person confrontations that may lead to violence, did not correlate with our outcome. The same was found concerning the development of online 
feuds; online feuds did not appear to be associated with shootings on the street. Unlike some of the results of recent examinations (Patton et al. 2019), we find that it is not the explicitly violent rhetoric directed at identifiable parties that correlated with shootings. Instead, the significant associations were linked to the overall tenor and tone of the gang's presence on social media. Here, for example, the overall measures of violent and illegal content that were believed to characterize the online presence of the gang were found to be significant.

It may be the case that threats on social media activity are more easily dismissed as puffery and posturing (Densley 2013; Felson 2006) and not such a viable threat that rivals feel compelled to respond in the immediate. Alternatively, this may be because violent rhetoric may be rejected as more performative than similar activities by gangs, especially in the more anonymous and less inhibited online space (Stuart 2020; but see Patton et al. 2017b). A more concrete and ongoing discussion of illegal activity, which here includes the display of cash and weapons without threats, could have been seen as a more definitive indicator of viable criminality and less as online chatter. These types of activities may be seen as openly and genuinely contemptuous of law enforcement as well (Sandberg and Ugelvik 2016). When backed up with pictures, posts openly displaying illegality may simply reflect more criminally active gangs (and so they are more likely to find its members in an encounter or scenario that develops into a shooting), given the clear ties between online conduct and lived experience (e.g., Roks et al. 2020). This may be especially true when the more overly violent commentary comes from gangs that are younger (though the differences here are small and could be practically insignificant). Future studies should explore these preliminarily identified relationships more deeply, and, where possible, within a causal framework.

The results of this study also provide support for some of the currently hypothesized theoretical frameworks that may link online activity by gang members to violence on the streets, especially shootings. From a Differential Association perspective, firstly, social media might function to increase the frequency, duration, and intensity of face-to-face gang communications (McCuddy and Esbensen 2020). It may also increase exposure to unique or online-only gang associations, thus introducing members to individuals with different constructions of definitions favorable toward crime, the acceptability of violence, and the necessity of having firearms. At the very least, social media create the illusion of proximity, connectivity, and having a large audience, both locally and internationally, that far exceeds the opportunities available using offline communications. In the current data, we see this reflected in the extent of overall usage of social media, as well as the number of "impact" players who are present in these online forums. The usage of social media is nearly universal among the gangs in this sample, suggesting that their audience and influences may be both evolving in a difficult-to-predict direction.

When considering these results from a Routine Activities perspective, we also find evidence for a relationship between online activity and violence. In this study that the presence of gang members on social media is hardly benign: threats, overt criminal activity, and other illegal behaviors are reported as being commonplace in this sample. Generally, gang members report high rates of offending and victimization in online settings, including harassment, intimidation, and violent threats (Pyrooz et al. 2015), an outcome supported by these gang-level activity data. Given the extent of usage, in the social media age, it is likely that individuals in these gangs are tasked with creating a continuous stream of gangrelated content for consumption as one of their duties of gang membership (Storrod and Densley 2017). On the one hand, this might incapacitate gang members for a short period by keeping them focused on their screens instead of on the street. However, as Lauger and Densley (2018) observed in their content analysis of YouTube rap videos produced by gangs in upstate New York, the internet is a natural extension of the street in part because it meets the symbolic needs of gang members as a status enhancer. Short-term benefits may be lost as the give-and-take between social media and the street becomes a basic function of gang life. The fact that gang reputations can now be quantified by the number 
of followers, likes, and retweets creates incentives to "do gang" (Lauger and Densley 2018) and "perform" gang membership for status or to save face (Van Hellemont 2012). This raises the prospect that gang members are "taken in by their own act" and find themselves unable to break character on the street, no matter the invasiveness of, or potentially benefits inherent in, engaging in a violence-reduction intervention (Goffman 1959). The impact on street shootings for the gangs more deeply engrained in this way of thinking is possibly reflected in the correlations observed here.

Lauger et al. (2020), using General Strain Theory as their guide, argue that threatening or insulting online material becomes a tension that is more likely to incite violence when it is seen as unjust, high in magnitude, is associated with low social control, and creates pressure or incentives for criminal coping. For example, in The Digital Street, Lane (2018) argues that social media has not only blurred the boundaries between the physical and virtual worlds but has extended Anderson (1999) "code of the street" online (see also, Urbanik and Haggerty 2018). Here, the correlations, albeit limited, between some measures of social media usage and shootings support the robustness of this relationship. This relationship goes in both directions; previous survey research has shown that gang members who are more invested in the code of the street are also more likely to respond violently to online threats, (Moule et al. 2017). In another study, gang-involved youth interpreted "dissing" (content that humiliates and degrades), "calling out" (content that challenges or questions someone's reputation or social status), and "direct threats" as the most threatening forms of communication on Twitter (Patton et al. 2019). In this case, the gangs with higher degrees of "impact" players engaging online, perhaps a proxy for gang-level investment, was one of the stronger correlates with an increased number of shootings during focused deterrence. The resulting actions by gang members, unlike the messages themselves, may spill out onto the streets as shootings as the result of these increased digital tensions

Finally, and perhaps most usefully, these results provide a foundation for a reconsideration of how focused deterrence specifically, and gang violence reduction policy more generally, can take these issues into account. In many ways, the keystone of focused deterrence is the messaging about the consequences to gang members if any member commits a shooting (as well as the benefits of abstaining, including the services that are typically made available). Practically, when certain members of the gang are "called in" to hear these propositions from law enforcement and community leaders, it is assumed that they will transmit the message to others in their gang and that this message will be heard. Here, given the correlations found, the near-constant drone of social media chatter may be "drowning out" that message for certain gangs.

The extent to which a gang actively engages with social media may, in itself, be a useful proxy for the extent to which gangs are willing to disregard or are unable to internalize the messaging in focused deterrence. Given the way law enforcement has responded to internet activity, actively posting illegal content, especially postings designed to flaunt criminal behaviors or taunt rivals, is risky (Densley 2013). Therefore, this could serve as a signal that a gang's desire to be seen as violent or a threat to rivals may supersede the more practical, but distant, consequences communicated out in the focused deterrence messaging. (Sandberg and Ugelvik 2016). Practically, during focused deterrence public social media activity could be captured in near-real-time and examined at the gang, not the individual level. In this way, these data may provide data-driven feedback on how certain gangs are responding to the intervention. This may inform which gangs are "called in" for meetings under the focused deterrence guidelines in that jurisdiction.

Within an existing researcher-practitioner partnership, social media analysis can provide a useful opportunity to tailor a program or intervention to the realities of the street (Sierra-Arévalo and Papachristos 2017). The formative feedback and hypothesis development process, facilitated by independent researchers, can help better identify areas of the strategy (e.g., messaging, forums, community partners engaged) that might not be working, or that need differential focus to be more effective in reaching the unresponsive target gangs. In Philadelphia, for example, there was a strong emphasis on fidelity to the 
focused deterrence model, which had been collaboratively developed at the outset of the project period. While an important aspect when replicating a national model, this may have supported a focus on responding fully to each potential opportunity for a crackdown, leading to missed opportunities to flexibly adapt to the shifting realities on the street. Building in a process for the analysis and discussion of social media data may formalize such an opportunity in future iterations of focused deterrence.

Finally, the results of this descriptive analysis should bring these issues to the forefront for the justice system and community stakeholders seeking to understand how gangs communicate and whether and how aspects of social media use have a street component. Here, the types of social media posting that are most likely to be considered an immediate threat, including threats of violence, did not correlate with an increase in shootings during focused deterrence. Instead, it was a broader pattern of online engagement that best reflected an increased risk. The findings here should be interpreted with the proper caveats. There may be measurement errors or other unknown biases in the variables as constructed. For example, the variable constructed as a percentage of the number of a gang's postings that were violent is dependent on the assumption that the social media information collected by law enforcement appropriately represents the extent of a gang's social postings. Regardless, the study results underscore the potential value of holistically examining the holistic picture of a gang's internet activity as well as individual posts when seeking to understand how a particular gang may act in the future. These results do not, however, support the examination of social media usage at the individual level, as there are myriad methodological and ethical issues inherent in that approach. While there is a significant amount of research and policy development necessary to develop, examine, and evaluate the nature of these relationships, the current findings provide an impetus and justification for expanding the scope of this critical work.

\section{Limitations}

In addition to the limitation mentioned directly above on measurement error, there are additional limitations inherent in the data available and the methods used in the current analysis. First, it should be noted that this study includes only a small number of gangs overall, and the implementation of focused deterrence in Philadelphia was unique (see Roman et al. 2019, 2020). Additionally, the gangs studied were from one section of Philadelphia that may have unique norms and culture. This constrains the generalizability of the findings, both within the local context and to other cities. Secondly, and related to measurement error, the data that were gathered during both auditing processes are the best and, in some cases, the only data of this nature, but they have limitations. Audit data are inherently retrospective, represent the perspective of a small number of law enforcement officers and/or agency staff, are unverified outside of the auditing process (and could be unverifiable using administrative data), and do not include the perspectives of the justice-involved members that are described by these data. Additionally, the intrinsic uncertainty regarding actual internet usage and behaviors meant that much of the social media data were reduced to being estimated as categorical variables or using broad scales; this limits the precision of the data and results. Finally, the methods employed here provide only descriptive statistics or describe only correlations with shootings; these results are not causal and should not be interpreted as such. Even with these limitations, the outcome of this study sheds empirical light on a debated, but rarely measured, aspect of life for gang-involved individuals and provides an opportunity to reconsider the results of an effort to reduce shootings in Philadelphia.

\section{Conclusions}

Focused deterrence is a widely used intervention to reduce gang-related shootings. When implemented in Philadelphia, a quasi-experimental evaluation found a reduction in shootings across the community that comprised 14 targeted gangs. However, when examining the change in shootings by gangs, it becomes clear that not all gangs responded 
equivalently, with some demonstrating an increasing rate of known shootings during the assessment. Here, we find descriptive evidence that there are differences between those gangs that responded well (i.e., a decrease in gang shootings) and those that did not regarding the nature and content of social media activity. When looking at all the participating gangs, we find that their overall level of engagement with social media, especially by high visibility gang members, was significantly correlated with a higher level of shootings during the implementation of focused deterrence. The variables that measured the posting of specific kinds of violent content, on the other hand, did not reach significance. These findings provide preliminary evidence on the potentially mediating role that public, social media content may have on efforts to reduce gang shootings. While more robust and causal evidence is needed to further specify these relationships, the role of social media should not be ignored when developing harm-prevention interventions, including focused deterrence, for this population of gang-involved individuals.

Author Contributions: Conceptualization: J.M.H., J.A.D., C.G.R.; methodology: J.M.H., C.G.R.; formal analysis: J.M.H., C.G.R.; investigation: J.M.H., C.G.R.; writing—original draft preparation: J.M.H., J.A.D., C.G.R.; writing-review and editing: J.M.H., J.A.D., C.G.R.; project administration: J.M.H., C.G.R.; funding acquisition: C.G.R. All authors have read and agreed to the published version of the manuscript.

Funding: This research was supported by grant number 2013-IJ-CX-0056 awarded to Temple University by the United States Department of Justice, National Institute of Justice. Opinions or points of view expressed are those of the authors and do not necessarily reflect the official position or policies of the Department of Justice or Temple University.

Institutional Review Board Statement: IRB protocol 21979 was approved (original version) by the Temple University Review Board on 4 February 2015.

Acknowledgments: The authors gratefully acknowledge the support of their law enforcement partners, with special thanks to Matt York and the members of the Philadelphia Police Department's (PPD) South Gang Task Force, Deputy Commissioner Joel Dales, the PPD Central Intelligence Unit, and the PPD Research \& Analysis Unit. In particular, Matt York and his colleagues participated in an ongoing dialogue with the research team to examine the possible reasons behind the differences in levels of shootings observed during focused deterrence.

Conflicts of Interest: The authors declare no conflict of interest.

\section{References}

Anderson, Elijah. 1999. Code of the Street. New York: W.W. Norton and Company.

Bock, Joseph G. 2012. The Technology of Nonviolence: Social Media and Violence Prevention. Cambridge: MIT Press.

Braga, Anthony. 2008. Pulling levers focused deterrence strategies and the prevention of gun homicide. Journal of Criminal Justice 36: 332-43. [CrossRef]

Braga, Anthony, and David L. Weisburd. 2012. The effects of focused deterrence strategies on crime: A systematic review and meta-analysis of the empirical evidence. Journal of Research in Crime and Delinquency 49: 323-58. [CrossRef]

Braga, Anthony, Jack McDevitt, and Glenn L. Pierce. 2006. Understanding and preventing gang violence: Problem analysis and response development in Lowell, Massachusetts. Police Quarterly 9: 20-46. [CrossRef]

Braga, Anthony, David Hureau, and Andrew Papachristos. 2014. Deterring gang-involved gun violence: Measuring the impact of Boston's Operation Ceasefire on street gang behavior. Journal of Quantitative Criminology 30: 113-39. [CrossRef]

Braga, Anthony, David Weisburd, and Brandon Turchan. 2018. Focused deterrence strategies and crime control: An updated systematic review and meta-analysis of the empirical evidence. Criminology \& Public Policy 17: 205-50.

Brayne, Sarah. 2017. Big data surveillance: The case of policing. American Sociological Review 82: 977-1008. [CrossRef]

Corsaro, Nicholas, and Robin S. Engel. 2015. Most challenging of contexts: Assessing the impact of focused deterrence on serious violence in New Orleans. Criminology \& Public Policy 14: 471-505.

Decker, Scott. 1996. Collective and normative features of gang violence. Justice Quarterly 13: 243-64. [CrossRef]

Decker, Scott, David Pyrooz, and James Densley. 2021. On Gangs. Philadelphia: Temple University Press.

Densley, James. 2013. How Gangs Work. New York: Palgrave Macmillan.

Densley, James. 2020. Collective Violence Online: When Street Gangs Use Social Media. In The Handbook of Collective Violence: Current Developments and Understanding. Edited by Carol Ireland, Michael Lewis, Anthony Lopez and Jane Ireland. London: Routledge, pp. 305-16. 
Densley, James, and David Jones. 2016. Pulling Levers on Gang Violence in London and St. Paul. In Gang Transitions and Transformations in an International Context. Edited by Cheryl Maxson and Finn-Aage Esbensen. Cham: Springer, pp. 291-305.

Densley, James, and David Pyrooz. 2020. The Matrix In Context: Taking Stock Of Police Gang Databases In London and Beyond. Youth Justice 20: 11-30. [CrossRef]

Deuchar, Ross. 2013. Policing Youth Violence: Transatlantic Connections. London: IOE Press.

Dewing, Michael. 2010. Social Media: An Introduction. Ottawa: Library of Parliament, vol. 1.

Eckberg, Deborah, James Densley, and Katrinna Dexter. 2018. When Legend Becomes Fact, Tweet the Legend: Information and Misinformation in the Age of Social Media. Journal of Behavioral and Social Sciences 5: 148-56.

Fedushko, Solomiia, Tomáš Peráček, Yuriy Syerov, and Olha Trach. 2021. Development of Methods for the Strategic Management of Web Projects. Sustainability 13: 742. [CrossRef]

Felson, Marcus. 2006. The Street Gang Strategy. In Crime and Nature. Edited by Marcus Felson. Thousand Oaks: Sage, pp. 305-24.

Frey, William R., Desmond U. Patton, Michael B. Gaskell, and Kyle A. McGregor. 2020. Artificial intelligence and inclusion: Formerly gang-involved youth as domain experts for analyzing unstructured twitter data. Social Science Computer Review 38: 42-56. [CrossRef]

Goffman, Erving. 1959. The Presentation of Self in Everyday Life. New York: Anchor.

Goldman, Liran, Howard Giles, and Michael A. Hogg. 2014. Going to extremes: Social identity and communication processes associated with gang membership. Available online: https://journals.sagepub.com/doi/abs/10.1177/1368430214524289 (accessed on 19 April 2021).

Graham, William. 2016. Global Concepts, Local Contexts: A Case Study of International Criminal Justice Policy Transfer in Violence Reduction. Available online: http:/ / ethos.bl.uk/OrderDetails.do?did=1\&uin=uk.bl.ethos.726773 (accessed on 19 April 2021).

Gravel, Jason, and George E. Tita. 2015. With great methods come great responsibilities: Social network analysis in the implementation and evaluation of gang programs. Criminology and Public Policy 14: 559. [CrossRef]

Harding, Simon. 2014. The Street Casino. Bristol: Policy Press.

Howell, James. 2007. Menacing or Mimicking? Realities of Youth Gangs. Juvenile and Family Court Journal 58: 39-50. [CrossRef]

Irwin-Rogers, Kier, James Densley, and Craig Pinkney. 2018. Gang Violence and Social Media. In The Routledge International Handbook of Human Aggression. Edited by Jane Ireland, Philip Birch and Carol Ireland. Abingdon: Routledge, pp. 400-10.

Johnson, Joseph, and Natalie Schell-Busey. 2016. Old Message in a New Bottle: Taking Gang Rivalries Online Through Rap Battle Music Videos on YouTube. Journal of Qualitative Criminal Justice and Criminology 4: 42-81.

Kennedy, David M. 2009. Gangs and public policy: Constructing and deconstructing gang databases. Criminology E Public Policy 8: 711.

Kennedy, David. 2019. Policing and the lessons of focused deterrence. In Police innovation: Contrasting Perspectives. Cambridge: Cambridge University Press, pp. 205-26.

Kennedy, David, Anne Piehl, and Anthony Braga. 1996. Youth violence in Boston: Gun markets, serious youth offenders, and a use-reduction strategy. Law and Contemporary Problems 59: 147-96. [CrossRef]

Kennedy, David, Anthony Braga, and Anne Piehl. 2001. Developing and Implementing Operation Ceasefire. In Reducing Gun Violence: The Boston Gun Project's Operation Ceasefire; Edited by U.S. Department of Justice Office of Justice Programs. Washington, DC: U.S. Department of Justice, pp. 5-54.

Lane, Jeffrey. 2018. The Digital Street. New York: Oxford University Press.

Lane, Jeff, Fanny Ramirez, and Katy Pearce. 2018. Guilty by Visible Association: Socially Mediated Visibility in Gang Prosecutions. Journal of Computer-Mediated Communication 23: 354-69. [CrossRef]

Lauger, Tim, and James Densley. 2018. Broadcasting Badness: Violence, Identity, and Performance in the Online Gang Rap Scene. Justice Quarterly 35: 816-41. [CrossRef]

Lauger, Tim, James Densley, and Richard Moule. 2020. Social Media, Strain, and Technologically-Facilitated Gang Violence. In The Palgrave Handbook of International Cybercrime and Cyberdeviance. Edited by Adam Bossler and Thomas Holt. New York: Palgrave Macmillan, pp. 1375-95.

Leverso, John, and Yuan Hsiao. 2020. Gangbangin On The [Face]Book: Understanding Online Interactions of Chicago Latina/o Gangs. Journal of Research in Crime and Delinquency. [CrossRef]

McCuddy, Timothy, and Finn-Aage Esbensen. 2020. The Role of Online Communication Among Gang and Non-gang Youth. In Gangs in the Era of Internet and Social Media. Edited by Chris Melde and Frank Weerman. Cham: Springer, pp. 81-104.

Melde, Chris, and Frank Weerman. 2020. Gangs in the Era of Internet and Social Media. Cham: Springer.

Moule, Richard, David Pyrooz, and Scott Decker. 2013. From “What The F\#@\% Is A Facebook" To "Who Doesn't Use Facebook?": The Role of Criminal Lifestyles in The Adoption Of The Use Of The Internet. Social Science Research 42: 1411-21. [PubMed]

Moule, Richard, David Pyrooz, and Scott Decker. 2014. Internet Adoption and Online Behaviour Among American Street Gangs: Integrating Gangs And Organizational Theory. British Journal of Criminology 54: 1186-206. [CrossRef]

Moule, Richard, Scott Decker, and David Pyrooz. 2017. Technology and Conflict: Group Processes and Collective Violence in the Internet Era. Crime, Law and Social Change 68: 47-73. [CrossRef]

Nakamura, Kiminori, George Tita, and David Krackhardt. 2020. Violence in the "balance": A structural analysis of how rivals, allies, and third-parties shape inter-gang violence. Global Crime 21: 3-27. [CrossRef]

Nickerson, Raymond. 1998. Confirmation Bias: A Ubiquitous Phenomenon in Many Guises. Review of General Psychology 2: 175-220. [CrossRef] 
Papachristos, Andrew. 2011. Too big to fail: The science and politics of violence prevention. Criminology E Public Policy $10: 1053$.

Papachristos, Andrew, and David S. Kirk. 2015. Changing the street dynamic: Evaluating Chicago's group violence reduction strategy. Criminology \& Public Policy 14: 525-58.

Pariser, Eli. 2011. The Filter Bubble. New York: Penguin.

Patton, Desmond, Robert Eschmann, and Dirk Butler. 2013. Internet Banging: New Trends in Social Media, Gang Violence, Masculinity and Hip Hop. Computers in Human Behavior 29: A54-A59. [CrossRef]

Patton, Desmond, Robert Eschmann, Caitlin Elsaesser, and Eddie Bocanegrad. 2016. Sticks, Stones and Facebook Accounts: What Violence Outreach Workers Know About Social Media and Urban-Based Gang Violence in Chicago. Computers in Human Behavior 65: 591-600. [CrossRef]

Patton, Desmond, Douglas-Wade Brunton, Andrea Dixon, Reuben Miller, Patrick Leonard, and Rose Hackman. 2017a. Stop and Frisk Online: Theorizing Everyday Racism in Digital Policing in The Use of Social Media for Identification of Criminal Conduct and Associations. Social Media and Society 3: 1-10. [CrossRef]

Patton, Desmond, Jeffrey Lane, Patrick Leonard, Jamie Macbeth, and Jocelyn Smith Lee. 2017b. Gang Violence on the Digital Street: Case Study of a South Side Chicago Gang Member's Twitter Communication. New Media and Society 19: 1000-18. [CrossRef]

Patton, Desmond, Owen Rambow, Jonathan Auerbach, Kevin Li, and William Frey. 2018. Expressions of Loss Predict Aggressive Comments on Twitter Among Gang-Involved Youth in Chicago. NPJ Digital Medicine 1: 11. [CrossRef]

Patton, Desmond, David Pyooz, Scott Decker, William Frey, and Patrick Leonard. 2019. When Twitter Fingers Turn to Trigger Fingers: A Sociolinguistic Study of Internet-Mediated Gang Violence. International Journal of Bullying Prevention 1: 205-17. [CrossRef]

Pawelz, Janina, and Paul Elvers. 2018. The Digital Hood of Urban Violence: Exploring Functionalities of Social Media and Music among Gangs. Journal of Contemporary Criminal Justice 34: 442-59. [CrossRef]

Peterson, Jillian, and James Densley. 2017. Cyber Violence: What Do We Know and Where Do We Go From Here? Aggression and Violent Behavior 34: 193-200. [CrossRef]

Pyrooz, David, and Richard Moule. 2019. Gangs and Social Media. Oxford Research Encyclopedia of Criminology and Criminal Justice. [CrossRef]

Pyrooz, David, Scott Decker, and Richard Moule. 2015. Criminal and Routine Activities in Online Settings: Gangs, Offenders, and the Internet. Justice Quarterly 32: 471-99. [CrossRef]

Roks, Robby, Rutger Leukfeldt, and James Densley. 2020. The Hybridization of Street Offending in the Netherlands. British Journal of Criminology. [CrossRef]

Roman, Caterina G., Nathan W. Link, Jordan M. Hyatt, Avinash Bhati, and Megan Forney. 2019. Assessing the gang-level and community-level effects of the Philadelphia Focused deterrence strategy. Journal of Experimental Criminology 15: 499-527. [CrossRef]

Roman, Caterina G., Megan Forney, Jordan M. Hyatt, Hannah J. Klein, and Nathan W. Link. 2020. Law Enforcement Activities of Philadelphia's Group Violence Intervention: An Examination of Arrest, Case Processing, and Probation Levers. Police Quarterly 23: 232-61. [CrossRef]

Sandberg, Sveinung, and Thomas Ugelvik. 2016. Why Do Offenders Tape their Crimes? Crime and Punishment in the Age of the Selfie. British Journal of Criminology 57: 1023-40. [CrossRef]

Sierra-Arévalo, Michael, and Andrew V. Papachristos. 2015. Applying group audits to problem-oriented policing. In Disrupting Criminal Networks: Network Analysis in Crime Prevention. Edited by Gisela Bichler and Aili E. Malm. Boulder: Lynne Rienner, pp. 27-46.

Sierra-Arévalo, Michael, and Andrew V. Papachristos. 2017. Social networks and gang violence reduction. Annual Review of Law and Social Science 13: 373-93. [CrossRef]

Storrod, Michelle, and James Densley. 2017. 'Going Viral' and 'Going Country': The Expressive and Instrumental Activities of Street Gangs on Social Media. Journal of Youth Studies 20: 677-96. [CrossRef]

Stuart, Forrest. 2020. Code of the Tweet: Urban Gang Violence in the Social Media Age. Social Problems 67: 191-207. [CrossRef]

Tita, George E., and Steven M. Radil. 2011. Spatializing the social networks of gangs to explore patterns of violence. Journal of Quantitative Criminology 27: 521-45. [CrossRef]

Tita, George E., K. Jack Riley, and Peter Greenwood. 2003. From Boston to Boyle Heights: The Process and Prospects of a ‘Pulling Levers' Strategy in a Los Angeles Barrio. In Policing Gangs and Youth Violence. Edited by Scott H. Decker. Belmont: Wadsworth Publishing Company, pp. 102-30.

Urbanik, Marta, and Kevin Haggerty. 2018. \#It's Dangerous: The Online World of Drug Dealers, Rappers and the Street Code. The British Journal of Criminology 58: 1343-60.

Van Hellemont, Elke. 2012. Gangland Online: Performing the Real Imaginary World of Gangstas and Ghettos in Brussels. European Journal of Crime, Criminal Law and Criminal Justice 20: 159-73. [CrossRef]

Whittaker, Andrew, James Densley, and Karen Moser. 2020. No Two Gangs are Alike: The Digital Divide in Street Gangs' Differential Adaptations to Social Media. Computers in Human Behavior 110: 106403. [CrossRef]

Williams, Damien J., Dorothy Currie, Will Linden, and Peter D. Donnelly. 2014. Addressing gang-related violence in Glasgow: A preliminary pragmatic quasi-experimental evaluation of the Community Initiative to Reduce Violence (CIRV). Aggression and Violence Behavior 19: 686-91. [CrossRef]

Zuboff, Shoshana. 2018. The Age of Surveillance Capitalism. New York: Public Affairs. 